\title{
How Can Texts in Classical Chinese Literature Help Create an Educational Space?
}

\section{Fan Chushu}

Saint-Petersburg State University

\begin{abstract}
As elite talents of the 21 st century should not only be experts in certain aspects, more importantly, they must have good aesthetic abilities. Aesthetic sense is not a skill that is useful for a moment, but a way of thinking that can be penetrated in all aspects of life, and benefit for life long time. Nevertheless, how to cultivate children with good aesthetic sense in school? Through classical literature is an excellent method. As educational space plays a magnificent role in any schools for children. In this article, we will look at how texts of classical Chinese literature can help to create an educational space based on the five human senses theory.
\end{abstract}

Keywords: How Can Texts in Classical Chinese Literature Help Create an Educational Space?

\section{Introduction}

\section{Sensory theory}

Aristotle divides human senses into five categories: touch, smell, taste, hearing and vision. Since different people have different strengths in sensory, Dr. Montessori created the method of education. He found that children grow up through their feelings, Dr. Montessori also said that sensory learning must be carried out through the concept of sensory formation. Thanks to this method, children can make creative choices in their study, while the teachers offer appropriate way to guide the teaching process.

\section{Design of school space}

Based on the sensory theory, we can elaborate on campus space design from the following aspects:

\section{Text (vision)}

The most intuitive way is to extract classic fragments or motto from classical literary works. Though these fragments, students can feel the beauty and power of literature. Sometimes, the texts can be introduction of poets or famous writers.

\section{Painting (vision)}

Many classic Chinese literatures, especially some ancient poetry, have a very beautiful artistic conception. Therefore, great paintings allow students to better understand these classic literatures. For example, there are numerous Chinese poems about the Chinese Great Wall, the landscape painting as below can help students understand how magnificent it is.

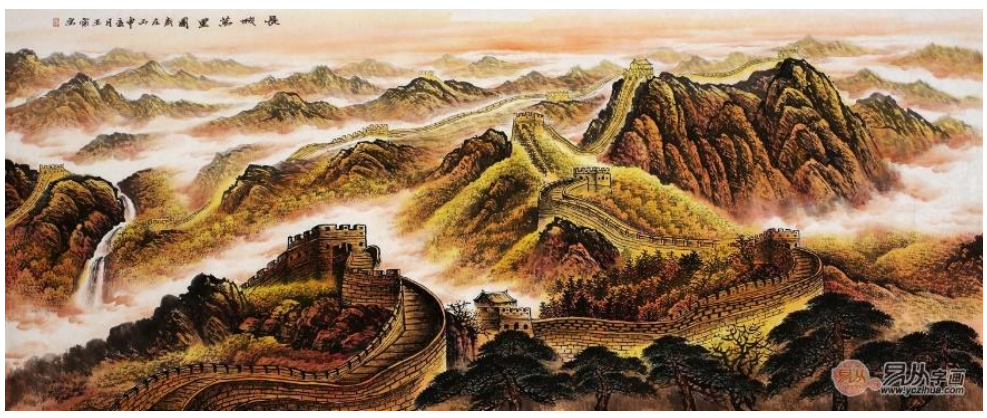




\section{Text of new nature (complex- vision, hearing)}

Today we have moved into a qualitatively new stage because of the fast development of modern multimedia. Thus, the text of new nature has been given birth. Texts of new nature, in contrast to traditional visual ones, they synthesize words and images. Comics adored by children; filmstrips, once loved by their parents; book trailers - video introduction of books; the pages of literary heroes on social networks; modern graphic novels, sketch notes are all texts of a new nature. Children and teenagers like new nature texts a lot, as they are more interesting, and easier to perceive. Thus, in the school space this is a good way to ask the students to create their own new nature texts, to introduce or present a classic literary work.

\section{Music (hearing)}

There are many classic ancient poems in China. Ancient poetry requires strict rhythm, so they are very catchy, and suitable to take them as lyrics. The combination of music and classic literature allows students to feel the harmonious beauty of the classical literature more deeply. In addition, can also make it easier for students to remember the poems with melody.

\section{Attributes (touching, tasting)}

In the school space the attributes can be red lantern, Chinese traditional folding fans, kites, paper cuttings, Chinese knots, embroidery, ect., which often appear in classical literatures. Those attributes are the crystallization of Chinese ancient wisdom, that embody the traditional Chinese aesthetic. We use them in decorating the school space, so that our students are able to touch and observe them closely, from which they can better understand the historical and cultural background of the literature works. They can even use them to play a fragment of certain classical literature.

More importantly, we should design the school space from the perspective of students. To entre their world, really consider their feelings and urgent needs. Dedicate to create an environment where our students can feel happy and warm.

\section{Conclusion}

Humans recognize the world through their senses. Thus, the educational space, as the place providing study environment, plays an important role for students. We should start from the perspective of the children, use as many texts, paintings, music, attributes as possible, to make an open educational space to help our students learn classical literatures, and enhance their aesthetics. 